\title{
Effects of $\beta$-agonists on dose-response curves
}

\section{To the Editor:}

Wong et al. [1] suggest that regular use of short- or long-acting $\beta$-agonists could increase the risk of a "precipitous asthma episode" associated with "breakthrough" bronchoconstriction. However, their data do not support this conclusion.

Firstly, their study shows that regular treatment with salbutamol for 4 days had no significant effect on the methacholine dose-response curve (DRC), compared to the postsalbutamol challenges at baseline, either in provocative concentration causing a $20 \%$ fall in forced expiratory volume in one second (FEV1) (PC20) or maximal response plateau. The authors suggest that regular salbutamol increased the slope of the DRC, compared to placebo. However, their data suggest that this difference is in fact due to a decrease in slope during treatment with placebo, and there is no difference in slope between the two postsalbutamol challenges (Figure 1 of their paper).

Secondly, the study shows that after 4 days treatment, $50 \mu \mathrm{g}$ salmeterol has less protective effect against

\section{REPLY}

From the authors:

In our study [1], two sets of dose-response slopes to methacholine challenge were obtained under different conditions. The first set of screening challenges were obtained prior to randomization of the subject into the double-blind study. On one screening visit, the doseresponse slope was measured without any premedication, and on the second visit the dose response slope was obtained after premedication with two puffs of open label salbutamol 15 min prior to commencement of provocation. The purpose of these screening tests was to establish eligibility for the study, namely to show that the subject did have airway hyperresponsiveness to methacholine, and that, either with or without premedication with salbutamol, a plateau could be achieved. If these criteria were met, along with the other entry criteria stated in our paper, the subject was then randomized into the three-way placebo-controlled crossover study in which they received 4 days of salmeterol, 4 days of salbutamol, or 4 days of placebo. The analysis compared the dose response slopes after each of these 4 day treatment periods, which were separated by at least 10 day washout periods.

As noted by Salome and Woolcock, the slope of the DRC after 4 days of placebo was less steep than after 4 days of salmeterol and salbutamol, as we reported. However, they then compare the slope of the DRC after 4 days of placebo with the slope of the DRC during the unpremedicated screening challenge, and note that the slope after the 4 days of placebo treatment had dec- methacholine than does $200 \mu \mathrm{g}$ salbutamol. However, since the investigators failed to measure a postsalmeterol methacholine DRC at baseline, it is not possible to tell if this difference is the result of tolerance developed during regular treatment or to a difference in the protective effect of different drugs at different doses.

This study provides no evidence that regular treatment with short- or long-acting bronchodilators had any deleterious effects on the methacholine dose-response curves in asthmatic subjects. The findings are "over interpreted" by the authors and the wording of the abstract suggests a clinical result that is not justified.

\section{References}

1. Wong AG, O'Shaughnessy AD, Walker CM, Sears MR. Effects of long-acting and short-acting $\beta$-agonists on methacholine dose-response curves in asthmatics. Eur Respir J 1997; 10: 330-336.

\section{Salome, A. Woolcock}

Department of Medicine, University of Sydney, NSW 2006, Australia.

reased, compared with baseline. They suggest that the finding we reported of a greater slope during $B$-agonist treatment was spurious because of this change during placebo treatment.

In conducting randomized controlled trials, comparisons must be conducted among data collected in situations where all factors are maintained stable apart from the intervention. There may be several reasons why the slope following the 4 day placebo treatment period differed to that at baseline. We have reported the relevant analyses, which are comparisons of dose-response slopes following the three blinded treatment periods. Comparison of slopes between the treatment periods and the initial screening baseline period are less valid but, as reported in the original paper, there were no statistically significant differences between the responses to challenge following 4 days of placebo and the untreated baseline response, nor between the responses to challenge following single-dose salbutamol and that after 4 days salbutamol treatment.

Challenge following a single dose of salbutamol was required as part of the baseline screening. We did not study the effect of a single dose of salmeterol as the study was not designed to look for tachyphylaxis, which has been shown by other studies $[2,3]$.

Our conclusion remains that salmeterol did not reduce the plateau and slightly increased the slope of the response compared to placebo, more so in those with lower FEV1. Hence this study suggests the potential for a more precipitous asthma episode if a bronchoconstrictor stimulus breaks through the partial bronchoprotection provided by salmeterol. 


\section{References}

1. Wong AG, O'Shaughnessy AD, Walker CM, Sears MR. Effects of long-acting and short-acting $\beta$-agonists on methacholine dose-response curves in asthmatics. Eur Respir J 1997; 10: 330-336.

2. Cheung D, Timmers MC, Zwinderman AH, Bel EH, Dijkman JH, Sterk PJ. Long-term effects of a long-acting $\beta$-adrenoreceptor agonist, salmeterol, on airway hyper- responsiveness in patients with mild asthma. $N$ Engl $J$ Med 1992; 327: 1198-1203.

3. Bhagat R, Kalra S, Swystun VA, Cockcroft DW. Rapid onset of tolerance to the bronchoprotective effect of salmeterol. Chest 1995; 108: 1235-1239.

\section{A.G. Wong, M.R. Sears}

Firestone Regional Chest and Allergy Unit, St Joseph's Hospital, McMaster University, Hamilton, Ontario, Canada. 